\title{
Quaternary Ammonium Polyelectrolytes: Thermal Behavior of Certain Systems ${ }^{\dagger}$
}

\author{
Bhim Bali Prasad,* Shirley Easo, and Anil Kumar \\ Analytical Division, Department of Chemistry, \\ Faculty of Science, Banaras Hindu University, \\ Varanasi-221 005, India
}

(Received May 7, 1993)

\begin{abstract}
Thermal analyses of four new class of crystal violet and bipyridinium cationic polyelectrolytes have been carried out in order to explore their stability and degradation behavior in air. Of these, two polyelectrolytes which have $\mathrm{N}$-acyl ammonium/imminium ions appeared moderately stable than those possessing $\mathrm{N}$-alkyl-ammonium ions in their respective repeating chains. The $N$-acyl-ammonium oligomers consisting thiophenylene linkages, however, showed unusual stability even at much higher than room temperature; this apparently opens an interesting class of widely useful thermally stable nitrogen-based polycationic systems. A correlation has been made to rationalize TG and DTA data in terms of the chain flexibility (segmental motion) of the macroions and the steric compressions involved in the conformation of their individual molecules.

KEY WORDS Nitrogen-Based Polyelectrolytes / Thermal Properties / Chain

Flexibility / Resonance Stabilization /
\end{abstract}

Over the years, studies on polyelectrolytes have developed into a major field of interest as these substances represent a unique class of ionic polymers. Unlike simple salts, polyelectrolytes contain macromolecules which carry a large number of ionic charges-the polyions-associated with equivalent number of counterions to satisfy electroneutrality. Quite reasonably, the thermal studies on these systems could be considered more interesting due to their relevance to problems encountered in fabrication of polymers into fibres, films, coatings and adhesives, etc.

The present article describes the thermal characteristics of certain quaternary ammonium polyelectrolytes having (i) charged nitrogen centres on the backbone of the macroions and not as side chain substituents, (ii) backbone quaternary centres constituting a parallel cationic track with quaternized nitrogens of the side groups of the molecular chain and (iii) heterocyclic ring nitrogens carrying the positive charges in the repeating, unit of the chain. Materials which satisfy the first two requirements are based on crystal violet structures with interspersed ethylene, xylylene and 2,5diacylthiophenylene links in the present investigation; whereas the third type has the said thiophenylene rings alternating 4,4'-bipyridinium (viologen) units in its molecular framework. These structural distinctions amongst the systems studied might impart interesting thermal characteristics depending upon the chain flexibility and steric hindrances in the individual molecular conformation.

\section{EXPERIMENTAL}

The following four linear nitrogen-based polycationic electrolytes (abbreviated as A, B,

† Recommended paper for Professor A. K. Dey Award, 1991 to S. Easo who presented at the 28th Annual Convention of Chemists, Jadavpur University, 1991.

* To whom correspondence should be addressed. 


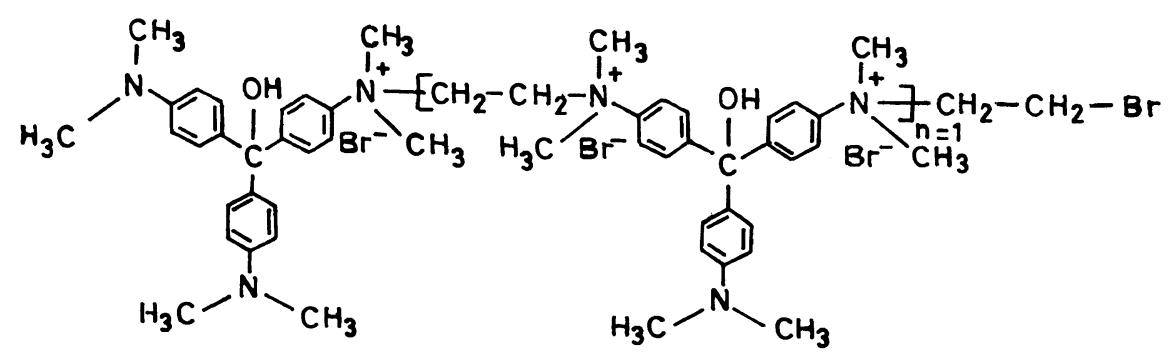

$(A: \operatorname{mol} w t=1154)$

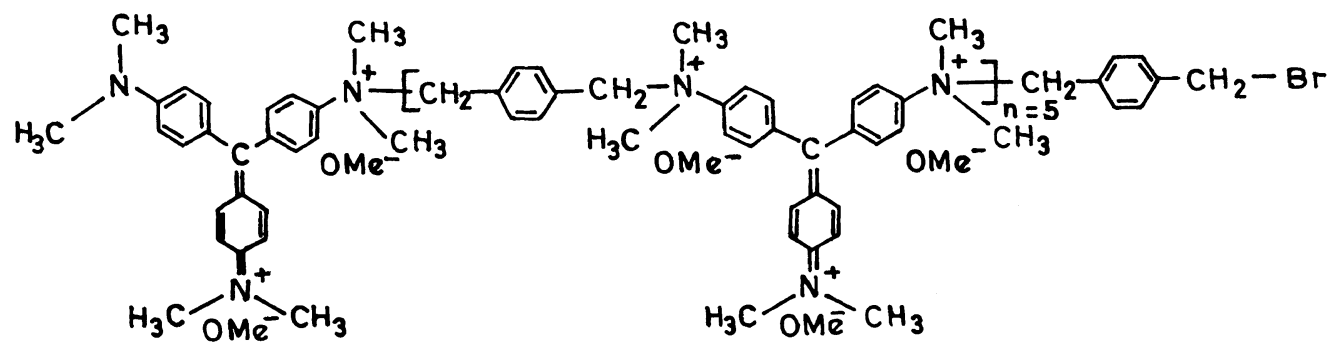

(B: $\operatorname{mol} w t=3463$ )

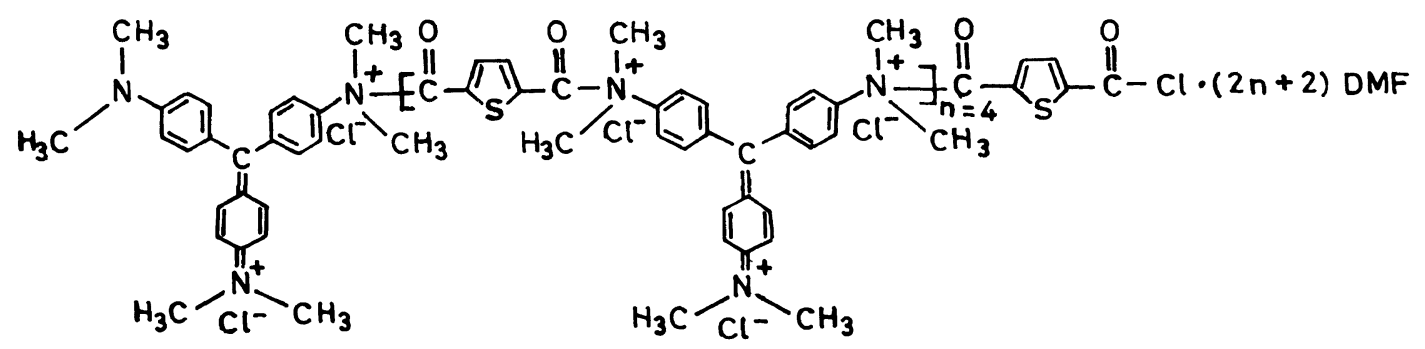

(C: mol $w t=3815$ )

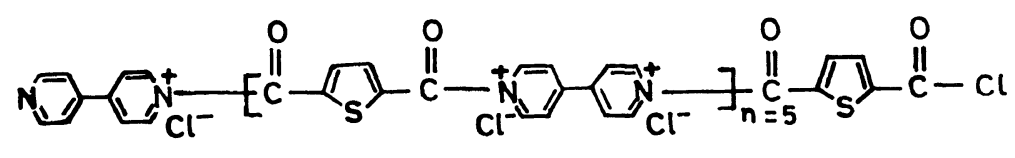

(D: mol wt $=2190)$

Figure 1. Chemical structures of nitrogen-based polyelectrolytes.

C, and D) are chosen for the present study and those chemical structures are shown in Figure 1: A, poly $[N$-ethylene monohydroxy crystal violet dibromide $]$; $\mathrm{B}$, poly $[N$ - $p$-xylylene crystal violet trimethoxide $]$; $\mathrm{C}$, poly $[N-2,5$-diacylthiophenylene crystal violet trichloride]; $\mathrm{D}$, poly[N-2,5-diacylthiophenylene 4,4'-bipyridinium dichloride]. These compounds were synthesized by the straightforward condensation of crystal violet or $4,4^{\prime}$-bipyridine and $\alpha, \alpha^{\prime}$-dihalogen compounds ( viz. 1,2-dibromoethane; $\alpha, \alpha^{\prime}$ dibromo-p-xylene and thiophene 2,5-dicarboxylic acid chloride) based on Menschutkin reactions. ${ }^{1}$ Structures (A, B, C, D) of these compounds were proposed on the basis of elemental and IR analyses. Details of synthesis and characterization have been reported earlier. ${ }^{2}$ The degree of polymerization of these 
compounds was determined through conductometric titrations by ascertaining the number of moles of counterions available per thousand grams of the sample. ${ }^{2,3}$ These compounds were found to be oligomers with total degree of polymerization $(n+1)$ ranging from 2 to 6 . Thin layer chromatographic analysis of compounds A, B, C, and D in butanol-acetic acid-water $(80: 15: 5)$ solvent mixture revealed only one spot after development in iodine chamber which provided additional verification of the purity and monodispersity of the compounds.

TG and DTA curves were recorded simultaneously with a Stanton Red-Croft thermal analyser STA 781 (U.K.) model in air at a heating rate of $10^{\circ} \mathrm{Cmin}^{-1}$. The standard material used as reference was sintered aluminium oxide $\left(\alpha-\mathrm{Al}_{2} \mathrm{O}_{3}\right)$. In each run, $8-12 \mathrm{mg}$ of samples was used in a platinum holder (crucible). The percentage change in weight as well as $\Delta T\left(T_{\text {sample }}-T_{\text {reference }}\right)$ were calculated for various temperatures from the original recordings and then plotted to obtain the concerned thermograms.

\section{RESULTS AND DISCUSSION}

TG and DTA curves of polyelectrolytes A, B, C, and D are showen in Figures 2-5. Table I compares thermal properties of these systems in air.

Table I suggests the order of thermal stability of the polyelectrolytes as $\mathrm{A}>\mathrm{B}>\mathrm{C}>\mathrm{D}$. The

Table I. Comparative evaluation of thermal stabilities of crystal violet and 4,4'-bipyridinium polyelectrolytes in air

\begin{tabular}{cccccc}
\hline & \multicolumn{4}{c}{ Temperature $\left({ }^{\circ} \mathrm{C}\right)$ for weight loss (\%) } \\
\cline { 2 - 6 } System & 20 & 40 & 50 & 70 & $\begin{array}{c}\text { Maximum } \\
\text { weight loss }\end{array}$ \\
& & & & & \\
\hline A & 370 & 445 & 510 & - & $765(60 \%)$ \\
B & 303 & 405 & 440 & 610 & $800(90 \%)$ \\
C & 230 & 270 & 290 & 460 & $685(100 \%)$ \\
D & 250 & 269 & 277 & 290 & $484(98 \%)$ \\
\hline
\end{tabular}

higher thermal stability for system A compared to other polyelectrolytes is justified in terms of its compact conformation with smaller chain length $(n=1)$. Compound $\mathrm{A}$ has quaternary ammonium centres with linear ethylene link-

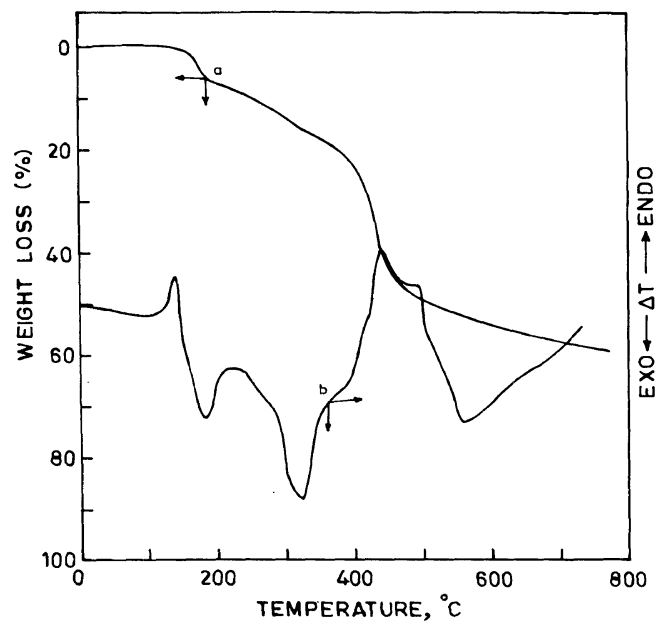

Figure 2. Thermogravimetric and differential thermal analysis of poly $[N$-ethylene monohydroxy crystal violet dibromide]: TG curve (a), DTA curve (b), heating rate $10^{\circ} \mathrm{Cmin}^{-1}$, atmosphere air, sample weight $11.80 \mathrm{mg}$, residue weight $4.80 \mathrm{mg}$.

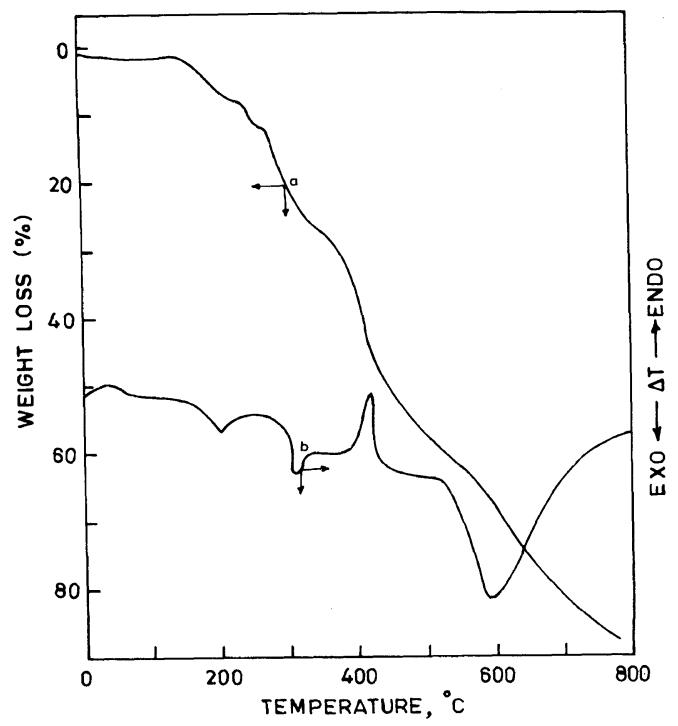

Figure 3. Thermogravimetric and differential thermal analysis of poly[ $N$-p-xylylene crystal violet trimethoxide]: TG curve (a), DTA curve (b), heating rate $10^{\circ} \mathrm{Cmin}^{-1}$, atmosphere air, sample weight $8.22 \mathrm{mg}$, residue weight $1.12 \mathrm{mg}$. 
ages involving less steric hindrance and moreover its pendant moieties carrying basic dimethylamine groups are essentially uncharged. This apparently imparts additional rigidity and hence stability to the dimeric system owing to intramolecular force of electrostatic attractions between the backbone quaternized nitrogen centres and uncharged pendant nitrogens carrying lone pair of electrons. In other systems $\mathrm{B}$ and $\mathrm{C}$, the backbone quaternary nitrogen centres are attached with aromatic xylylene and 2,5-

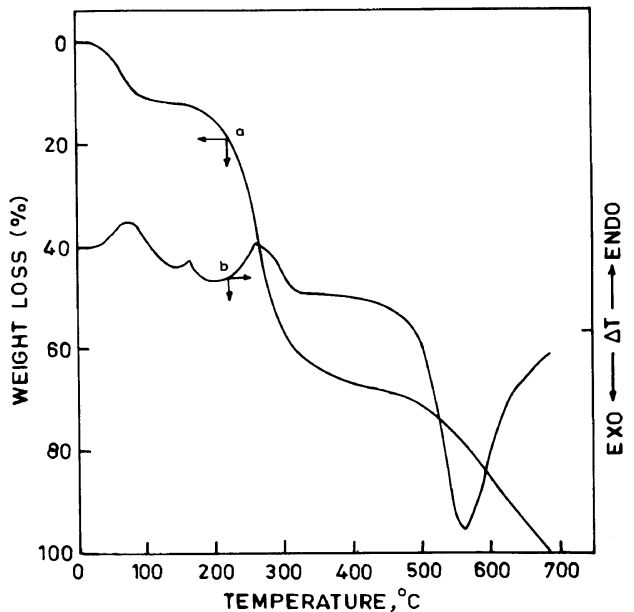

Figure 4. Thermogravimetric and differential thermal analysis of poly[ $N$-2,5-diacylthiophenylene crystal violet trichloride]: TG curve (a), DTA curve (b), heating rate $10^{\circ} \mathrm{Cmin}^{-1}$, atmosphere air, sample weight $10.20 \mathrm{mg}$, residue weight $0.00 \mathrm{mg}$.

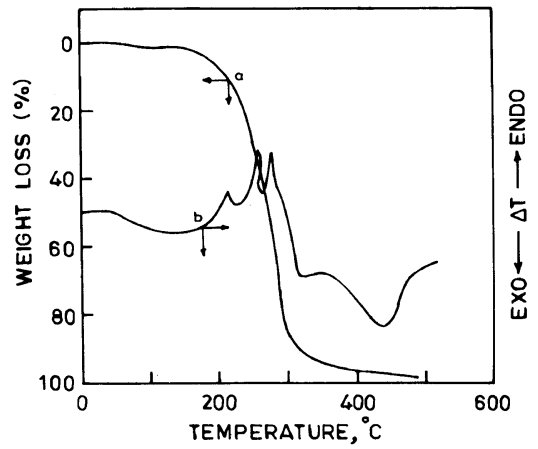

Figure 5. Thermogravimetric and differential thermal analysis of poly[ $N$-2,5-diacylthiophenylene 4,4'-bipyridinium dichloride]: TG curve (a), DTA curve (b), heating rate $10^{\circ} \mathrm{Cmin}^{-1}$, atmosphere air, sample weight $8.60 \mathrm{mg}$, residue weight $0.24 \mathrm{mg}$. diacylthiophenylene linkages respectively and constituting a track of positive centres along with the positively charged side groups $(2,5-$ cyclohexadiene-1-ylidene- $N$-methylmethanaminium ions) of the crystal violet moieties present in the structure. Therefore, compounds $\mathrm{B}$ and $\mathrm{C}$ might exert intramolecular electrostatic repulsion between parallel track of positive centres paving the way for an easier degradation on heating. Furthermore, bulkier xylylene or thiophenylene residues present in respective structures also pose serious steric compressions in $\mathrm{B}$ and $\mathrm{C}$ causing higher instability as compared to A.

Insofar as the acyl compounds are concerned, there are many instances of $N$ acylammonium or $n$-acylpyridinium salts ${ }^{4}$ which are reported to be highly unstable above $0^{\circ} \mathrm{C}$. However, the present set of compounds $\mathrm{C}$ and $\mathrm{D}$, which possess $\mathrm{N}$-acylammonium and $\mathrm{N}$-acyliminium bonds respectively in their polymeric networks, showed markedly stable (solid) nature well beyond the room temperature. This might be attributed specifically to the presence of 2,5-thiophenylene linkages<smiles>CN(C)C(=O)c1ccc(C(=O)N(C)C)s1</smiles>
(c)

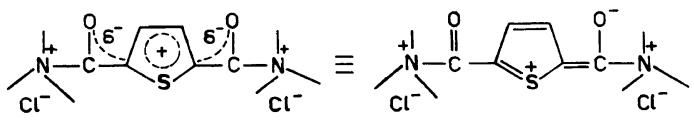<smiles>C[n+]1ccc(-c2cc[n+](C(=O)c3ccc(C(=O)n4ccc(-c5cc[n+](C)cc5)c4)s3)c(Cl)c2)cc1</smiles><smiles>C[n+]1ccc(-c2cc[n+](C([O-])(c3ccc(C([O-])[n+]4ccc(Cl)cc4)s3)[n+]3ccc(-c4cc[n+](C)cc4)cc3Cl)cc2)cc1</smiles>

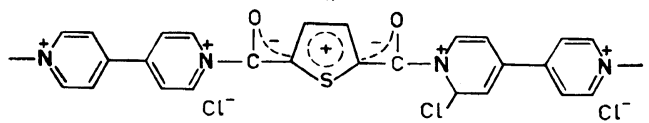

Figure 6. Resonance stabilization of poly $[N-2,5$-diacylthiophenylene crystal violet trichloride] (compound $C$ ) and poly $[N-2,5$-diacylthiophenylene 4,4'-bipyridinium dichloride] (compound D). 
in these compounds which impart stability through resonance stabilized intramolecular electrostatic binding, ${ }^{4,5}$ as shown in Figure 6. The proposed resonance stabilization results in an increased conjugation with partial double bond character of the substituents in 2,5positions and hence the rigidity of thiophene linkages. The additional forces that stabilize these structures are electrostatic (or salt) bonds formed between the opposite charged groups on the surface of the molecules. Although polyelectrolytes C and D containing 2,5diacylthiophenylene linkages may apparently have good resonance stability at room temperature, they seem to be more susceptible to thermal degradation beyond $175^{\circ}$ and $150^{\circ} \mathrm{C}$ respectively (Figures 4 and 5). The lower stability of the polyelectrolyte $\mathrm{D}$ is because of its flexible chain structure with higher degree of polymerization $(n=5)$ in which $N$-acyliminium bonds do not let the system to retain its segmental stiffness to the extent as that of C $(n=4)$ containing bulkier pendant side groups, on heating. Compounds $\mathrm{A}$ and $\mathrm{B}$ which possess $\mathrm{N}$-alkyl-ammonium linkages are found relatively stable upto $\sim 200^{\circ} \mathrm{C}$ (Figures 2 and 3 ). It is to be noted that compound B is found more thermally stable than $\mathrm{C}$ in spite of their somewhat comparable molecular weights and moreover, it is not compliant with the chain length and the degree of polymerization of $\mathrm{B}$ $(n=5)$ which is higher than those for $\mathrm{C}(n=4)$. This fact may be attributed to the difference in the resonance stabilization between benzene ring $\left(39 \mathrm{kcal} \mathrm{mol}^{-1}\right)$ and the thiophene ring $\left(28 \mathrm{kcal} \mathrm{mol}^{-1}\right)$. $^{6}$

Thermogravimetric analysis indicates that an initial loss of about $6-7 \%$ between $100-200^{\circ} \mathrm{C}$ for compound $\mathrm{A}, 2-7 \%$ around $50-200^{\circ} \mathrm{C}$ for $\mathrm{B}$ and $10 \%$ between $50-100^{\circ} \mathrm{C}$ for $\mathrm{C}$ is largely due to loss of moisture and/or entrapped solvent, if any, in the system. Thermal degradations of polyelectrolytes $\mathrm{B}$ and $\mathrm{C}$ follow complex patterns in which the maximum weight losses are observed beyond $200^{\circ} \mathrm{C}$ through several stages, while $\mathrm{A}$ and D decompose in one step with maximum weight loss during the range $200-600^{\circ} \mathrm{C}$ and $150-350^{\circ} \mathrm{C}$, respectively. Although the exact molecular chain degradation patterns of these compounds are not known, the major thermal cleavages may apparently be predicated along $N$-ethylene, $N$-xylylene, and $N$-acylthiophenylene linkages in all these systems. Furthermore, the extent of bond-ruptures appears to be relatively large in $\mathrm{B}$ and $\mathrm{C}$ due to steric reasons, since almost negligible $(0-10 \%)$ residues were left over after complete pyrolysis. Interestingly, the compound $\mathrm{A}$, however, exhibits only $60 \%$ constant weight loss with $\sim 40 \%$ total residue. This could be particularly attributed to the presence of $\mathrm{Br}^{-}$ions in $\mathrm{A}$ which might get readily oxidized to the molecular bromine causing an immediate heat-resistant action ${ }^{7}$ against further pyrolysis. Similar fire-resistance behaviour in systems $\mathrm{C}$ and $\mathrm{D}$ are surprisingly not favoured. This could be due to the non-availability of $\mathrm{Cl}^{-}$ions for oxidation as these are likely to be readily convertible before further ruptures into corresponding acid chlorides just after the cleavages of $N$ acylthiophenylene bonds; though there is no proof of such reaction.

Figures 2-5 also present DTA traces for systems A, B, C, and D while Table II summarizes the DTA characteristics of these compounds in air.

The DTA results corroborate the findings of thermogravimetry. The endothermic humps around 100,51 , and $80^{\circ} \mathrm{C}$ for $\mathrm{A}, \mathrm{B}$, and $\mathrm{C}$ correspond to the dehydration of the system (these compounds appear to absorb traces of moisture on exposure to air). The appreciable weight losses beyond $300^{\circ} \mathrm{C}$ or $500^{\circ} \mathrm{C}$ in various stages (Table II) accompanying the strong exothermic reactions indicate that the polymer matrices may undergo crystalline transition $\left(T_{\mathrm{c}}\right)$ and/or oxidative degradation $\left(T_{\mathrm{o}}\right)$ in air. All systems, however, also demonstrate an appreciable magnitude of weight loss through several endothermic changes in air. The glass transition temperatures $\left(T_{\mathrm{g}}\right)$ were tentatively 
Table II. DTA characteristics of the polyelectrolytes ${ }^{a}$

\begin{tabular}{|c|c|c|}
\hline \multirow{2}{*}{ System } & \multicolumn{2}{|c|}{ DTA peak at temperature $/{ }^{\circ} \mathrm{C}$} \\
\hline & Endothermic & Exothermic \\
\hline A & $\begin{array}{l}100-138(\text { sharp }), T_{\mathrm{d}}, T_{\mathrm{g}} \\
438(\text { broad }), T_{\mathrm{m}}\end{array}$ & $\begin{array}{l}184,320(\text { sharp}) T_{\mathrm{c}} \\
550(\text { sharp }), T_{\mathrm{o}}\end{array}$ \\
\hline B & $\begin{array}{r}51 \text { (broad), } T_{\mathrm{d}} \\
80 \text { (broad), } T_{\mathrm{g}} \\
419 \text { (sharp), } T_{\mathrm{m}}\end{array}$ & $\begin{array}{l}200,310(\text { small }) T_{\mathrm{c}} \\
593\left(\text { sharp), } T_{\mathrm{o}}\right.\end{array}$ \\
\hline $\mathrm{C}$ & $\begin{array}{l}80 \text { (broad), } T_{\mathrm{d}} \\
167(\text { sharp }), T_{\mathrm{g}} \\
260(\text { sharp }), T_{\mathrm{m}}\end{array}$ & 561 (sharp) $T_{\mathrm{o}}$ \\
\hline $\mathrm{D}$ & $\begin{array}{l}50 \text { (broad), } T_{\mathrm{g}} \\
215,255,280\left(\text { sharp) } T_{\mathrm{m}}\right.\end{array}$ & $\begin{array}{l}135 \text { (broad), } T_{\mathrm{c}} \\
315 \text { (broad) } T_{\mathrm{o}} \\
440 \text { (sharp) }\end{array}$ \\
\hline
\end{tabular}

a $T_{\mathrm{d}}=$ dehydration temperature; $T_{\mathrm{g}}=$ glass transition temperature; $T_{\mathrm{c}}=$ crystalline temperature; $T_{\mathrm{m}}=$ melting point; $T_{\mathrm{o}}=$ oxidation temperature.

assigned from DTA at $\sim 138,80,167$, and $50^{\circ} \mathrm{C}$ to systems A, B, C, and D, respectively. These values are understandably high as all compounds contain either bulky side groups or aromatic rings in their structure enhancing inflexibility of the system. Notwithstanding the fact that compound $A$ has more flexible ethylene units in the main chain, the significant intramolecular attractive forces between the main chain and pendant substituents and moreover the stacking property of the dye-tagged small molecules of $\mathrm{A}$ render a high degree of rigidity and crystallinity causing higher $T_{\mathrm{g}}$ and $T_{\mathrm{m}}$ values. Compounds $\mathrm{C}$ and $\mathrm{D}$ have interspersed polar groups in the structure. This results in higher $T_{\mathrm{g}}$ for C. However, similar extra polarity developed on account of the postulated resonance (Figure 6) would be of peripherial importance in $\mathrm{D}$ which has lowest stability amongst all systems studied as demonstrated by their $T_{\mathrm{g}}$ and $T_{\mathrm{m}}$ values. This may be due to an easier segmental motion ${ }^{8}$ in absence of any bulkier substituent in the linear structure of compound D.

The large differences between $T_{\mathrm{g}}$ and $T_{\mathrm{c}}$ values for A and B (Table II) display enough range of temperature to have rubber like property and within this temperature interval, these systems could be transformed into suitable membranes which provide effective ion-exchange sites, to be used in the fabrication of ion-sensors. ${ }^{9}$ In regard to the other crystal violet system $\mathrm{C}$, which is amorphous in nature, mobility of its segmental units appears to be highly restricted. This might be the reason that softening of the oligomer $\mathrm{C}$, i.e., the direct transition from glass to the viscofluid state $\left(T_{\mathrm{g}} \rightarrow T_{\mathrm{m}}\right)$ could be feasible through endothermic process (Table II). Nevertheless, coatings of these water-insoluble crystal violet-based polyelectrolytes nearby their respective $T_{\mathrm{g}}$ values may enhance their further scope as thermally stable ion-exchange materials in environmental analysis for anionic contaminants. Similarly, bipyridinium polyelectrolyte $\mathrm{D}$ could be also used as membrane or coating in the polymer-modified electrode to offer several "viologen" units as electronrelay materials. ${ }^{10}$

\section{REFERENCES}

1. E. Tsuchida, K. Sanada, and K. Moribe, Macromol. Chem., 151, 207 (1972).

2. B. B. Prasad, S. Easo, and A. Kumar, Polymer, 1993, under publication; S. Easo, Ph.D. Thesis, Banaras Hindu University (1992).

3. L. M. Mukherjee and B. B. Prasad, J. Macromol. Sci.-Chem., A19(3), 357 (1983).

4. A. N. Kost and S. I. Suminov, " $N$-Acyl Pyridinium Salts," in Iminium Salt in Organic Chemistry," $\mathrm{H}$. Böhme and H. G. Viehe, Ed., John Wiley, New York, N.Y., 1979, Part 2.

5. S. Gronowitz, "Recent Advances in the Chemistry of Thiophenes," in "Advances in Heterocyclic Chemistry," Vol. I, A. R. Katritzky, Ed., Academic Press, New York, N.Y., 1963, p 1.

6. W. R. Sorenson, J. Org. Chem., 24, 987 (1959).

7. B. N. Achar, G. M. Fohlen, and J. A. Parker, J. Polym. Mater., 2, 16 (1985).

8. A. Tager, "Physical Chemistry of Polymers," 2nd ed (English), Mir Publishers, Moscow, 1978, p 224.

9. N. Ishibashi and H. Kohara, Jpn. Anal., 21, 100 (1972); K. Kina, N. Machawa, and N. Ishibashi, Bull. Chem. Soc. Jpn., 46, 2772 (1973); N. Ishibashi, H. Kohara, and K. Horinouchi, Talanta, 20, 867 (1973); N. Ishibashi and A. Jyo, Microchem. J., 18, 220 (1973).

10. L. A. Summers, J. Heterocyclic Chem., 28, 827 (1991). 